\title{
Pollen fertility and seed viability of putative hy- brid swarms of Pinus sylvestris and Pinus mugo in Slovakia
}

\author{
Andrej Kormutak ${ }^{1, *} \cdot$ Martina Brana ${ }^{2} \cdot$ Martin Galgoci ${ }^{1}$ Peter Manka $\cdot$ Denisa Sukenikova ${ }^{3} \cdot$ Jana \\ Libantova $^{1}$ • Dusan Gömöry ${ }^{5}$
}

\author{
${ }^{1}$ Plant Science and Biodiversity Centre SAS, Institute of Plant Genetics and Biotechnology, Akademicka 2, P. O. Box 39A, \\ SK-950 07 Nitra, Slovak Republic \\ ${ }^{2}$ Slovak Inspectorate of Environment, Regional Inspectorate in Bratislava, External Station in Nitra, Marianska dolina 7, \\ 94901 Nitra, Slovak Republic \\ ${ }^{3}$ Constantine Philosopher University in Nitra, Department of Botany and Genetics, A. Hlinku 1, SK-949 74 Nitra, Slovak \\ Republic \\ ${ }^{4}$ Ministry of Environment, Department of State Administration of Nature Protection, Nam. L. Stura 1, 81235 Bratislava, \\ Slovak Republic \\ ${ }^{5}$ Technical University in Zvolen, Faculty of Forestry, T. G. Masaryka 24, SK-960 53 Zvolen, Slovak Republic
}

*Corresponding author: Andrej Kormutak, e-mail: nrgrkorm@savba.sk

\begin{abstract}
Generally acknowledged reduction of the interspecific hybrid fertility was utilized in evaluation of the putative hybrid swarms of Scots pine (Pinus sylvestris L.) and mountain dwarf pine $(P$. mugo Turra) viability under field conditions. Pollen viability and seed quality of the trees from the four contact zones of $P$. sylvestris and $P$. mugo in Slovakia were compared with the corresponding characteristics of the pure populations of these species from three reference localities. Pollen germination percentage was comparable in contact zones and control populations of the species. Statistically significant differences between the parent and hybrid groups were detected in pollen tube length only. In general, pollen tubes of the pure species populations were longer than those in contact zones. At the cone level, the individuals from contact zones possessed shorter cones than the trees of pure species populations $P$. mugo and $P$. sylvestris. This was paralleled by a lower number of seeds per cone in contact zones and higher amount of seeds per cone in the $P$. mugo population. Striking differences between individuals of the contact zones and reference populations were revealed also in germination potentials of their seeds. Significantly higher proportions of germinating seeds was found in the reference populations of $P$. mugo and $P$. sylvestris than in their contact zones. Contrary to seed quality parameters mentioned above, the fractions of filled but non-germinating seeds and amounts of empty seeds were higher in contact zones than in the parental species populations, indicating higher frequency occurrence of abortive embryogenesis in the
\end{abstract}

former. The lower fertility characteristics of the individuals from contact zones indicate their hybrid nature.

Keywords: : Pinus mugo, P. sylvestris, contact zones, fertility

\section{Introduction}

Discussing sterility problems of interspecific hybrids in his chapter on hybridism, Darwin (1859) concluded that some degree of sterility is extremely general, but not a universal result of species hybridization. According to Stebbins (1950), the distinguishing feature of interspecific hybrid sterility is that it is always present and differs relatively little depending on which individuals of the parental species are used for crossing. The author discriminates among sterile interspecific hybrids a group of hybrids which are completely sterile, and those which are capable to produce some viable pollen and seed through selfing, intercrossing between $F_{1}$ individuals, or backcrossing to the parental species. Interspecific hybrids of pines seem to belong to the second category of hybrids, as evidenced by recent studies on pine interspecific hybrid fertility (White et al., 2009). An extensive study on meiosis, involving 21 species and 22 interspecific hybrid combinations of both soft and hard pines, revealed higher frequencies of pollen abortion in hybrid trees than in pure species. The highest values for aborted pollen were associated with the highest frequencies of meiotic irregularities (Saylor and Smith, 1966). At seed level, Politov et 
al. (1999) reported a 25 percent share of empty seeds in the hybrid swarm $P$. pumila $\times P$. sibirica in the Bajkal lake area, with a much higher share of empty seeds in the hybrid swarm than in the parental species. Also, a total seed set of the hybrid swarm mentioned above was substantially reduced in comparison with the parental species (Goroshkevich, 2004). In Middle Europe, the hybrid swarms of pines refer exclusively to the taxonomically related species $P$. sylvestris and $P$. mugo of the section Pinus, subsection Sylvestres, of the hard pines (Little and Critchfield, 1969). Being the members of karyologically homomorphic genus Pinus $(2 \mathrm{n}=24)$, the species were reported to exhibit a high degree of karyological similarity (Sax and Sax, 1933). Although karyologically similar, the species $P$. sylvestris and $P$. mugo are morphologically and ecologically distinct taxa. The former is a tree-like pine with a single stem and a large distribution area in northern Eurasia, while the latter is a smaller, multi-stemmed pine, often of a shrub-like habitus, with natural distribution ranging from the Pyrenees through the Alps and Apennines to the Carpathians (Mirov, 1967). In Slovakia, P. sylvestris is a typical tree of the lowlands and hills, with altitudinal distribution between $230 \mathrm{~m}$ and $700 \mathrm{~m}$ (Blatny and Stastny, 1959). The species P. mugo dominates subalpine ecosystems in the central and northern parts of the country, forming upper timber line at $1800 \mathrm{~m}$. The lower limit of its natural distribution is at $1550 \mathrm{~m}$ (Somora, 1981). However, due to extrazonal occurrence, these species meet on several places of northern Slovakia where they may intercross sporadically. According to Boratyński et al. (2003), there is a 10-day shift in phenology of $P$. mugo reproductive organs compared to those of $P$. sylvestris in the region. This shift does not prevent crosspollination and gene flow from $P$. sylvestris towards $P$. mugo and, to some extent, also reciprocally. The populations evolved in this way are currently designated as putative hybrid swarms. In Poland, the hybrid nature of these swarms is postulated on the basis of morphology and anatomy of their needles (Staszkiewicz, 1996; Bobowicz et al., 2000), needle proteins and isoenzymes (Prus-Głowacki and Szweykowski, 1980; Prus-Głowacki et al., 1981), and occurrence of chloroplast DNA (cpDNA) haplotypes in sympatric populations of the parental species $P$. sylvestris, P. mugo, and P. uliginosa (Wachowiak and Prus-Głowacki, 2008). In Switzerland, Christensen and Dar (1997) proved the primary hybrid nature of suspected spontaneous hybrids of $P$. mugo $\times P$. sylvestris using morphometric analysis of their needle anatomic traits. Likewise, an extensive anatomic study on needles of individual trees of the putative hybrid swarm population Medzi Bormi near Zuberec in Slovakia has provided a strong evidence supporting hybrid status of this population (Viewegh, 1981). The population was shown to produce the pollen grains with reduced size and viability (Kormutak et al., 2008). Among seed characteristics, the yield of filled seeds and seed germination rate were reduced significantly in the three putative hybrid swarms of $P$. sylvestris and $P$. mugo in Slovakia in comparison with control populations of the parental species (Kormutak et al., 2009). The genetic status of suspected hybrid swarms of these pines in Slovakia has not been settled definitely, but the data on pollen and seed quality indicate their hybrid origin. This validates the idea of partially reduced fertility of interspecific hybrids and/or hybrid swarms of pines as one of the most conspicuous and challenging attribute of their reproductive behavior. As a support to this concept, we are presenting experimental evidence indicating considerable reduction of pollen viability and seed quality in the four putative hybrid swarms of $P$. sylvestris and $P$. mugo occurring in Slovakia.

\section{Materials and Methods}

\section{Species and populations used}

A comparative study on pollen fertility and seed viability involved the putative hybrid swarm populations of Scots pine (Pinus sylvestris L.) and mountain dwarf pine (P. mugo Turra) growing on the peat-bog localities Medzi Bormi near Zuberec, Tisovnica near Oravska Polhora, and Sucha Hora in the northern Orava region, Slovakia. The area of these localities is 6.5 ha, 2.0 ha, and 4.5 ha, respectively. In addition, at Sokolie near Terchova in the Mala Fatra Mountain Ridge, a putative hybrid swarm occurs on the calcareous rocks, covering the area of 4.0 ha.

\section{Table 1}

List of species and populations used in the experiment

\begin{tabular}{|c|c|c|c|c|}
\hline Species/populations & Locality & Altitute & Latitude & Longitude \\
\hline P. mugo & Vratna valley & $1381 \mathrm{~m}$ & $49^{\circ} 13^{\prime} 20^{\prime \prime}$ & $19^{\circ} 02^{\prime} 05^{\prime \prime}$ \\
\hline P. mugo & Rohace & $1450 \mathrm{~m}$ & $49^{\circ} 12^{\prime} 27^{\prime \prime}$ & $19^{\circ} 44^{\prime} 30^{\prime \prime}$ \\
\hline P. sylvestris & Hrustin & $700 \mathrm{~m}$ & $49^{\circ} 19^{\prime} 52^{\prime \prime}$ & $19^{\circ} 20^{\prime} 53^{\prime \prime}$ \\
\hline Putative hybrid swarm & Medzi Bormi & $815 \mathrm{~m}$ & $49^{\circ} 16^{\prime} 25^{\prime \prime}$ & $19^{\circ} 37^{\prime} 14^{\prime \prime}$ \\
\hline Putative hybri swarm & Tisovnica & $810 \mathrm{~m}$ & $49^{\circ} 20^{\prime} 32^{\prime \prime}$ & $19^{\circ} 45^{\prime} 51^{\prime \prime}$ \\
\hline Putative hybrid swarm & Sucha Hora & $765 \mathrm{~m}$ & $49^{\circ} 23^{\prime} 20^{\prime \prime}$ & $19^{\circ} 47^{\prime} 11^{\prime \prime}$ \\
\hline Putative hybrid swarm & Sokolie & $1172 \mathrm{~m}$ & $49^{\circ} 14^{\prime} 45^{\prime \prime}$ & $19^{\circ} 01^{\prime} 24^{\prime \prime}$ \\
\hline
\end{tabular}

The neighbour populations of $P$. sylvestris in Hrustin along with P. mugo populations in Rohace and Vratna valley served as a control (Table 1). They represent extensive natural stands of the respective pines in the country located $15-110 \mathrm{~km}$ apart from the putative hybrid swarms. An overwhelming majority, but not all trees which had been sampled for pollen viability, were also used for seed quality estimation.

\section{Pollen viability estimation}

Pollen was harvested from individual trees at the end of May and early June 2016. Of the seven populations compared, only two control localities and three contact zones were involved into the pollen study. We have missed the pollen shedding of $P$. mugo at Rohace and in the hybrid swarm at Sokolie. The number of sampled trees in individual localities ranged between 19 and 21 (Table 2). Majority of the trees in contact zones were clustered into clumps, especially those of $P$. mugo habitus, while other trees grew scattered, but in close vicinity to each other. A few individuals of each zone occupied a relatively solitary position. The control population P. sylvestris in Hrustin was 
relatively small, consisting of 90-100 trees only, as compared with the dense natural stands of $P$. mugo in Vratna valley and Rohace. Around 20 microstrobili were collected from each study tree shortly before pollen shedding. Collected strobili were wrapped in paper bags and transferred to the laboratory on the same day. Microstrobili of individual trees were laid out on a separate sheets and left 1-2 days to desiccate on a sunny side of the laboratory. Released pollen was sieved in a separate room, left additional 3-4 hours in the laboratory to desiccate, sealed in the vials, and stored at $4^{\circ} \mathrm{C}$ for five weeks prior to use in germination tests. In vitro germination test was employed in pollen viability estimation, using $1.5 \%$ agar and $10 \%$ sucrose as a cultivation medium. A total of $3.5 \mathrm{ml}$ of melted cultivation medium were pipetted into Petri dish of a 5-cm diameter. After solidification of the medium, the pollen was picked up from the stored vials using a soft painting brush and sown evenly over the medium surface by blowing. The open Petri dish with sown pollen was placed into a larger Petri dish $(7.5 \mathrm{~cm}$ diameter) containing $2 \mathrm{ml}$ of distilled water. The larger Petri dish was covered with a cap and placed into the incubator. Pollen of each tree was sampled in triplicate and incubated at $25^{\circ} \mathrm{C}$ for 48 hours. Microscopic evaluation of the samples involved 100 pollen grains of each replicate in pollen germination estimation and 30 pollen tubes in pollen tube length measurement, using a $7 \times$ eyepiece and a $10 \times$ objective. Except for germination percentage and pollen tube length, the occurrence of forked pollen tubes in individual trees was taken into account. No attempt was made to correlate the pollen viability characteristics with the seed quality of tested trees.

\section{Cone size measurement}

The number of trees tested within control populations of the parental species $P$. sylvestris and $P$. mugo as well as the number of trees of the putative hybrid swarms Medzi Bormi and Tisovnica ranged between 29 and 33. In the larger hybrid swarms Sokolie and Sucha Hora, the number of sampled trees was 55 and 52, respectively. The number of cones harvested from these trees varied considerably, mainly because of the reduced amounts of cones in some trees of the hybrid swarms. Only trees bearing at least seven cones were taken into account. For example, in the hybrid swarm Tisovnica, as many as 219 cones were obtained from 29 trees as compared with 1111 cones collected from 52 trees in the hybrid swarm Sucha Hora. The number of cones in pure species populations of $P$. sylvestris and P. mugo ranged between 658 and 1088 (Table 3). The cones of $P$. mugo and putative hybrid swarms were collected during September-October, while the cones of $P$. sylvestris were collected at the end of November of the same year. Cone length was measured immediately after harvesting, using a sliding ruler.

\section{Seed quality estimation}

Extracted seeds were germinated on moistened cotton-wool paper in Petri dishes at $25^{\circ} \mathrm{C}$. Each tree was represented in the germination test by 150 seeds. In particular, this was the case in the control populations P. mugo from Rohace and Vratna valley, with sufficient amounts of available seeds. The remaining populations were represented by the samples of individual trees with lower seed numbers, mainly because of their reduced fecundity, including the control population $P$. sylvestris in Hrustin. Except for germination rate, each sample was evaluated also with regard to the filled, but non-germinating seeds and empty seeds. Discrepancy between the number of individuals used in cone size measurement and those used in seed quality estimation (see Tables 3 and 4), was due to the absence of seeds in some cones of the trees subjected to analysis.

The obtained experimental data were statistically treated by the analysis of variance using ANOVA and Duncan grouping.

\section{Results}

\section{Pollen viability}

Almost all fertility characteristics of the putative hybrid swarms were lower in comparison with fertility of the control populations $P$. sylvestris and $P$. mugo. The percentage of germinating pollen grains varied considerably in both pure species and putative hybrid swarms, but the control population P. mugo from Vratna valley and the putative hybrid swarm Tisovnica contained the highest proportions of germinating pollen (Table 2). The pollen of control population $P$. sylvestris was comparable with the hybrid swarms rather than with P. mugo. The species $P$. sylvestris deviated slightly by its germination percentage from the hybrid swarms on the localities Medzi Bormi and Sucha Hora, but more profoundly from the percentage of germinating pollen in P. mugo. However, a more significant differentiation between control populations and hybrid swarms could be revealed in the pollen tube length parameter. The control populations P. mugo and P. sylvestris possessed the longest pollen tubes while the putative hybrid swarms much shorter pollen tubes. The differences were statistically significant (Table 2).

Table 2

Pollen germination characteristics in parental species $P$. mugo, P. sylvestris and in their hybrid swarms

\begin{tabular}{|c|c|c|c|c|c|c|}
\hline \multirow{3}{*}{$\begin{array}{l}\text { Species/populat } \\
\text { ions }\end{array}$} & \multirow[t]{3}{*}{ Locality } & \multirow{3}{*}{$\begin{array}{l}\text { Num } \\
\text { ber of } \\
\text { indiv. }\end{array}$} & \multicolumn{2}{|c|}{ Germination [\%] } & \multicolumn{2}{|c|}{ Pollen tube length $[\mu \mathrm{m}]$} \\
\hline & & & Mean \pm s.d. & Duncan & Mean \pm s.d. & Duncan \\
\hline & & & & test & & test \\
\hline P. mugo & Vratna v. & 20 & $94.68 \pm 3.8$ & $\bar{A}$ & $133.84 \pm 44.8$ & $\bar{A}$ \\
\hline P. sylvestris & Hrustin & 21 & $88.26 \pm 7.6$ & B & $123.00 \pm 43.3$ & B \\
\hline Hybrid swarm & M. Bormi & 21 & $87.65 \pm 19.7$ & $\mathrm{C}$ & $105.88 \pm 50.1$ & $\mathrm{C}$ \\
\hline Hybrid swarm & S. Hora & 19 & $86.19 \pm 19.3$ & $\mathrm{C}$ & $102.67 \pm 38.3$ & D \\
\hline Hybrid swarm & Tisovnica & 21 & $94.52 \pm 4.8$ & A & $103.04 \pm 40.1$ & D \\
\hline
\end{tabular}

Note: Different letters of Duncan test refer to statistical significancy of the differences between tested populations 
Analysis of variance revealed a substantial contribution of individual trees to the variability of the pollen tube length reaching $24.08 \%$. As much as $7.97 \%$ of this variation could be ascribed to the differentiation between the tested populations. Frequency occurrence of ramified pollen tubes among germinating pollen grains was highest in the $P$. mugo control population $(25.75 \%)$ followed by the hybrid swarm populations Tisovnica $(23.20 \%)$ and the $P$. sylvestris population in Hrustin (22.49\%). The hybrid swarms Medzi Bormi and Sucha Hora deviated in this respect conspicuously, possessing only 15.28 $\%$ and $14.15 \%$ of the forked pollen tubes (Fig. 1).

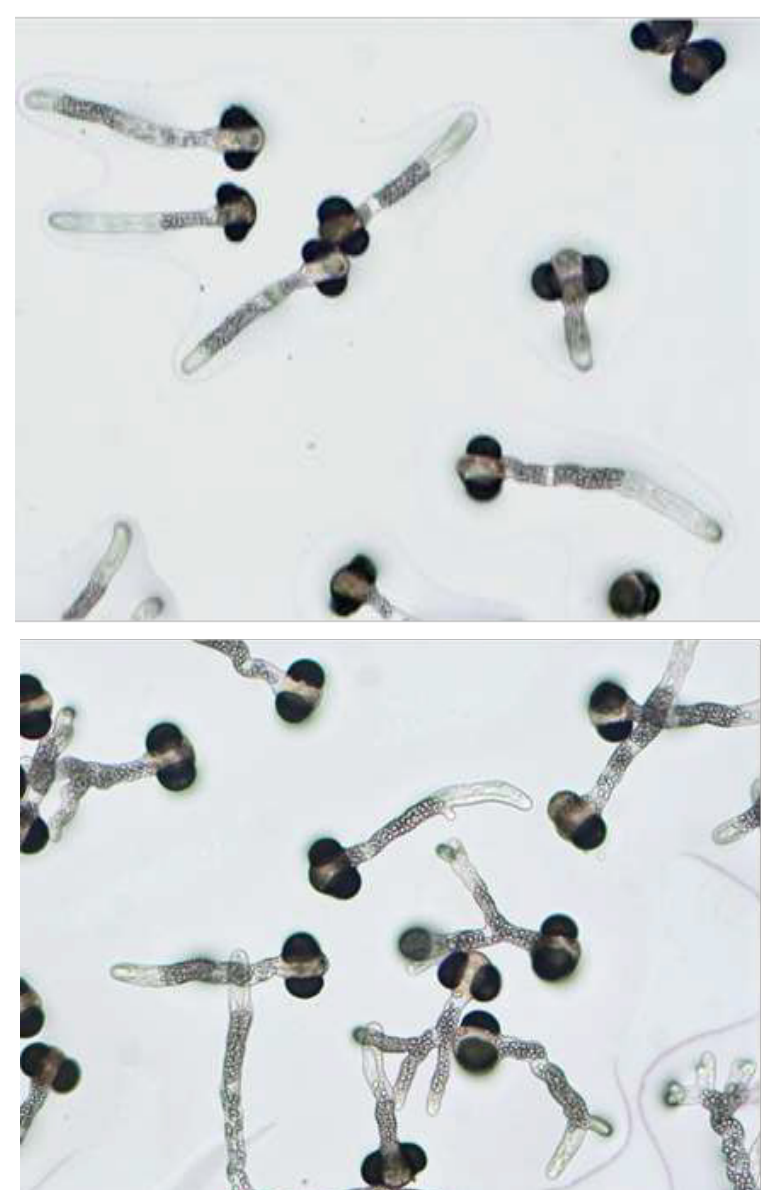

Fig. 1

Germinating pollen prains with single pollen tubes (up) and pollen grains with single and forked pollen tubes (down)

\section{Cone size and seed quality}

In contrast with pollen germination characteristics, the differences ascertained at the mature cone level enabled differentiation between control populations with larger cones and hybrid swarms with smaller cones in a more straight-forward way. The only exception was the $P$. mugo control population from Rohace whose cone size was comparable with those of hybrid swarms. The latter represented a relatively heterogenous group, which deviates profoundly by its smaller cones from the control populations P. sylvestris in Hrustin and P. mugo in Vratna valley (Table 3 ). The four hybrid swarm populations averaged in their cone length at $3.43 \mathrm{~cm}$ as compared with $3.83 \mathrm{~cm}$ long cones of the $P$. mugo populations from Vratna valley and Rohace and $4.38 \mathrm{~cm}$ long cones of $P$. sylvestris from Hrustin. Based on the results of Duncan test, all the three population groups exhibited statistically significant differences in their cone size $\left(F=16.88^{* * *}\right)$.

\section{Table 3}

Cone length in parental species P. mugo, P. sylvestris and in their hybrid swarms

\begin{tabular}{llcccc}
\hline Species/popul. & Locality & $\begin{array}{l}\text { Number of } \\
\text { trees }\end{array}$ & $\begin{array}{l}\text { Number of } \\
\text { cones }\end{array}$ & $\begin{array}{l}\text { Mean } \pm \text { s.d. } \\
{[\mathrm{cm}]}\end{array}$ & $\begin{array}{c}\text { Duncan } \\
\text { test }\end{array}$ \\
\hline P. sylvestris & Hrustin & 32 & 658 & $4.38 \pm 0.70$ & A \\
P. mugo & Vratna valley & 32 & 1088 & $4.14 \pm 0.48$ & B \\
P. mugo & Rohace & 33 & 1065 & $3.51 \pm 0.54$ & E \\
Hybrid swarm & Medzi Bormi & 32 & 503 & $3.74 \pm 0.82$ & C \\
Hybrid swarm & Sokolie & 55 & 940 & $3.16 \pm 0.56$ & F \\
Hybrid swarm & Sucha Hora & 52 & 1111 & $3.57 \pm 0.63$ & D \\
Hybrid swarm & Tisovnica & 29 & 219 & $3.12 \pm 0.54$ & F
\end{tabular}

Note: Different letters of Duncan test refer to statistical significancy of the differences between tested populations

The differences between control populations and hybrid swarms in terms of seed characteristics were much more distinct. As shown in Table 4, the two population groups may be distinguished on the basis of a total seed number per cone. The first group was represented by the $P$. mugo populations from Vratna valley and Rohace with the highest amounts of seeds per cone, while the second group was represented by the hybrid swarms Medzi Bormi, Tisovnica, and Sokolie with markedly lowered seed amounts. However, there are two exceptions. The control population $P$. sylvestris from Hrustin had a low seed number per cone, resembling the group of hybrid swarms rather than a control. Reversely, the hybrid swarm in Sucha Hora, with a higher seed number per cone, could be allocated among control populations (Table 4). 
Table 4

Seed quality parameters in populations of parental species $P$. mugo and P. sylvestris and in their hybrid swarms

\begin{tabular}{|c|c|c|c|c|}
\hline Variable & Species/populations & $\begin{array}{l}\text { Number } \\
\text { of indiv. }\end{array}$ & Mean \pm s. d. & $\begin{array}{l}\text { Duncan } \\
\text { test }\end{array}$ \\
\hline \multirow{7}{*}{$\begin{array}{l}\text { Seed number } \\
\text { per cone }\end{array}$} & P. mugo-Vratna valley & 32 & $43.01 \pm 15.0$ & A \\
\hline & P. mugo-Rohace & 33 & $27.74 \pm 13.0$ & B \\
\hline & P. sylvestris-Hrustin & 32 & $8.80 \pm 9.0$ & D \\
\hline & Hybr. swarm-M.Bormi & 32 & $9.89 \pm 8.1$ & $\mathrm{D}$ \\
\hline & Hybr. swarm-S. Hora & 52 & $22.67 \pm 15.0$ & $\mathrm{C}$ \\
\hline & Hybr. swarm-Tisovnica & 29 & $11.66 \pm 11.8$ & $\mathrm{D}$ \\
\hline & Hybr. swarm-Sokolie & 55 & $7.89 \pm 9.5$ & $\mathrm{D}$ \\
\hline \multirow[t]{7}{*}{ Germination [\%] } & P. mugo-Vratna valley & 32 & $82.32 \pm 14.0$ & A \\
\hline & P. mugo-Rohace & 33 & $54.68 \pm 14.8$ & B \\
\hline & P. sylvestris-Hrustin & 24 & $60.55 \pm 21.0$ & B \\
\hline & Hybr. swarm-M.Bormi & 27 & $36.81 \pm 23.3$ & $\mathrm{CD}$ \\
\hline & Hybr. swarm-S. Hora & 47 & $39.55 \pm 25.5$ & $\mathrm{C}$ \\
\hline & Hybr. swarm-Tisovnica & 21 & $29.21 \pm 22.0$ & $\mathrm{D}$ \\
\hline & Hybr. swarm-Sokolie & 39 & $10.91 \pm 11.2$ & E \\
\hline \multirow{7}{*}{$\begin{array}{l}\text { Filled seeds } \\
\text { non-germinating } \\
{[\%]}\end{array}$} & P. mugo-Vratna valley & 32 & $10.10 \pm 9.2$ & $\mathrm{C}$ \\
\hline & P. mugo-Rohace & 33 & $26.43 \pm 11.9$ & B \\
\hline & P. sylvestris-Hrustin & 24 & $23.42 \pm 16.9$ & B \\
\hline & Hybr. swarm-M.Bormi & 27 & $29.54 \pm 20.0$ & B \\
\hline & Hybr. swarm-S. Hora & 47 & $45.04 \pm 23.4$ & A \\
\hline & Hybr. swarm-Tisovnica & 21 & $48.09 \pm 20.4$ & A \\
\hline & Hybr. swarm-Sokolie & 39 & $47.98 \pm 16.3$ & A \\
\hline \multirow[t]{7}{*}{ Empty seeds [\%] } & P. mugo-Vratna valley & 32 & $7.57 \pm 7.5$ & E \\
\hline & P. mugo-Rohace & 33 & $18.87 \pm 9.8$ & $\mathrm{CD}$ \\
\hline & P. sylvestris-Hrustin & 24 & $16.01 \pm 11.8$ & $\mathrm{D}$ \\
\hline & Hybr. swarm-M.Bormi & 27 & $34.04 \pm 18.7$ & B \\
\hline & Hybr. swarm-S. Hora & 47 & $15.11 \pm 7.33$ & $\mathrm{D}$ \\
\hline & Hybr. swarm-Tisovnica & 21 & $23.65 \pm 13.6$ & $\mathrm{C}$ \\
\hline & Hybr. swarm-Sokolie & 39 & $41.10 \pm 16.7$ & A \\
\hline
\end{tabular}

Germination percentage, as the most important parameter of seed quality, has revealed even more significant differences between control populations and hybrid swarms. The proportion of germinating seeds of the control populations was incomparably higher than that of the hybrid swarms. The $10.9 \%$ of seed germination in the hybrid swarm from Sokolie has, for example, contrasted with the $82.3 \%$ of germinating seeds in the control population of P. mugo from the Vratna valley (Table 4). Further analysis of germinating seeds proved that the lower quality of hybrid swarm seeds is due to a highly frequent occurrence of both underdeveloped and empty seeds, indicating abortive embryogenesis. In the control populations $P$. mugo and $P$. sylvestris, the proportion of filled, but non-germinating seeds averaged at $10.10-26.43 \%$ as compared with
25.54-48.09\% of such seeds in hybrid swarms. Also, the proportion of empty seeds was increased in hybrid swarms (15.11$41.10 \%)$ in comparison with control populations (7.57-18.87 $\%)$. Summary of these differences is provided in Table 5. Based on these data, all seed quality parameters were higher in control populations than in hybrid swarms. Analysis of variance confirmed the statistical significance of the differences between species $\left(\mathrm{F}=41.14^{* * *}-100.04^{* * *}\right)$ and populations investigated $\left(F^{\prime}=10.40^{* * *}-28.46^{* * *}\right)$.

Table 5

Pooled data on seed quality in populations of parental species and in their hybrid swarms

\begin{tabular}{llcc}
\hline Variable & Species/populations & $\begin{array}{c}\text { Number of } \\
\text { individuals }\end{array}$ & Mean \pm s. d. \\
\hline $\begin{array}{l}\text { Seed number } \\
\text { per cone }\end{array}$ & P. mugo & 65 & $34.64 \pm 15.8$ \\
& $\begin{array}{l}\text { P. sylvestris } \\
\text { Hybrid swarms }\end{array}$ & 32 & $8.88 \pm 9.0$ \\
& & 168 & $13.48 \pm 13.1$ \\
Germination [\%] & P. mugo & 65 & $67.18 \pm 19.9$ \\
& P. sylvestris & 24 & $60.55 \pm 21.0$ \\
& Hybrid swarms & 134 & $29.04 \pm 24.2$ \\
Filled seeds & & & \\
non-germinating [\%] & P. mugo sylvestris & 65 & $19.05 \pm 13.5$ \\
& Hybrid swarms & 24 & $23.42 \pm 16.9$ \\
& & 134 & $43.25 \pm 21.3$ \\
& P. mugo & & \\
P. sylvestris & 65 & $13.76 \pm 10.4$ \\
& Hybrid swarms & 24 & $16.01 \pm 11.8$ \\
& & 134 & $27.83 \pm 17.7$
\end{tabular}

\section{Discussion}

Individual tree fertility can be measured by counting reproductive structures, such as female and male strobili, seed cones, and seeds. Each individual has its intrinsic fertility value, which is described as the ability to transmit genes to the offspring (Kang et al., 2003). In case of the putative hybrid swarms of $P$. sylvestris and $P$. mugo, it is believed that viability evaluation of their progenies may be of help in identifying hybrid individuals (Wachowiak et al., 2006). Also, genetic estimation of seeds or progenies from individuals in a hybrid zone makes it possible to estimate directly mating patterns among individuals (Baciliery et al., 1996). We have employed similar approaches in describing the putative hybrid swarms in terms of pollen viability and seed quality characteristics. Since hybrid sterility is considered to be one of the most significant characteristics that discriminate interspecific from intraspecific hybrids (Stebbins, 1950), the average values of pollen and seed quality are expected to be lower in the swarms in comparison with control populations of the parental species. Of the three pollen viability characteristics examined, only pollen tube length has satisfied this criterion discriminating between the control populations P. mugo from Vratna valley and/or P. sylvestris from Hrustin and their putative hybrid swarms in Zuberec, Sucha Hora, and Tisovnica. Pollen vitality of hybrid swarms was significantly 
reduced in this viability parameter in comparison with control populations, indicating the hybridity of the swarms. Exceptionally high germination potential revealed in pollen of the hybrid swarm Tisovnica resembles the pure species population rather than hybrid swarm but its pollen tube characteristics fall into the putative hybrid swarm framework. Methodical error associated with microscopic evaluation of germinating pollen seems to be one of the possible explanation of this discrepancy. In some other hybrids of pines, even a more profound reduction of pollen viability was reported. In the $P$. banksiana $\times$ $P$. contorta hybrid, an abnormal pollen percentage amounted 40-50 \% (Righter and Stockwell, 1949). The same figure was presented for 10 interspecific hybrids of pines by Duffield (1952). Of these, in the $P$. strobus $\times$ P. parviflora hybrid, pollen sterility averaged at $5 \%$ as compared with $30 \%$ of sterile pollen in the reciprocal cross P. parviflora $\times P$. strobus and $11 \%$ of sterile pollen in the $P$. griffithii $\times P$. strobus hybrid. On the contrary, in the hybrid between $P$. balfouriana and $P$. parviflora, pollen sterility was not greater than in pure parental species (Sax, 1960). Pollen germination ability in the putative hybrid swarms of Scots pine and mountain dwarf pine was not dramatically lowered, but shortened pollen tubes suggest decreased pollen vitality, which may adversely affect fertilizing potential of the pollen. Such pollen tubes fail in reaching the archegonium in open-pollinated ovules of the pines, thereby blocking fertilization process already at the prezygotic stage already (Dogra, 1967). Profound reduction of pollen viability in the putative hybrid swarm relative control stands of the pure parental species was revealed also in our previous studies. The differences concerned not only pollen tube length, but also germination percentage in sampled trees in Zuberec and Sucha Hora (Kormutak et al., 2007, 2008). Average values of germination percentage and pollen tube length vary annually, most probably due to variation in climatic conditions, but significant differences between populations of pure parental species on the one hand and their putative hybrid swarms on the other hand were preserved in both germination percentage and pollen tube growth or in one of the pollen viability parameters. Some tendency in frequency occurrence of forked pollen tubes could also be observed in the present study. A higher frequency of such pollen tubes was found in the control populations $P$. mugo and $P$. sylvestris rather than in hybrid swarms. However, it is still unclear, whether this phenomenon is species-specific or common in pines. Cytological studies on pollination biology and embryogeny in these trees revealed ramified pollen tubes in the nucellar tissue of pollinated ovules in several species (Chamberlain, 1935; Sarvas, 1962; Kormutak, 1984). Amoebalike growth of pollen tubes fills the tip of the nucellus almost entirely, enhancing physiological stimulus which is necessary for the ovules and conelets to survive the winter between their first and second growth periods.

Besides flowering, the reproductive success of a tree also depends on its ability to set seed and the ability of seeds to survive and grow into mature trees (Kang et al., 2003). This aspect of the putative hybrid swarm's reproductive cycle was investigated using seed quality characteristics. Being taxonomically related, the species $P$. sylvestris and $P$. mugo intercross sporadically in the mixed natural stands. Based on morphological assessment, around $10 \%$ of individuals with intermediate habitus between $P$. sylvestris and $P$. mugo were revealed in a group of 2000 trees evaluated by Danusevichius et al. (2012). Artificial hybridization attempts resulted in $16.8 \%$ of filled seeds of a $P$. sylvestris $\times P$. mugo crossing obtained by Moulalis et al. (1976) and/or in $1 \%$ of filled seeds obtained in the same crossing by Wachowiak et al. (2005). Rare as primary hybridization between these species seems to be, its outcome is the hybrid progeny named $P$. uncinata and/or $P$. uliginosa. The hybrid forms share a specific habitus and ability to grow on peatbogs (Businsky 1999). Introgressive hybridization between individuals of the above interspecific hybrid and the parental species was comparable in its efficiency with primary hybridization of the species. Using species-specific cpDNA restriction profiles of $P$. sylvestris and the hybrid form $P$. uliginosa, Wachowiak et al. (2005) revealed $1 \%$ of hybrid seedlings in the open pollinated progenies of $P$. uliginos $a$ and $2 \%$ hybrid seedlings in the open pollination progenies of the neighbour P. sylvestris population. Likewise,Wachowiak and Prus-Głowacki (2008) report of $1.7 \%$ of the hybrids $P$. uliginos $\times P$. sylvestris and a comparable fraction of the reciprocal hybrids in the open pollination progenies. Based on these findings, the authors postulate a rare hybridization between $P$. uliginosa and $P$. sylvestris. This may explain the lowered quality of seed crops in the putative hybrid swarms of Scots and mountain dwarf pines with introgressive hybridization of a varying intensity (Kormutak et al., 2008a). Due to prezygotic reproductive barriers between the hard pine species (Buchholz 1944), the ovules with dormant pollen grains undergo abortion during the first growing season, remaining as the rudimentary remnants on the ovuliferous scales of the conelets (Kriebel, 1967). Only ovules with germinating pollen grains whose pollen tubes penetrate the nucellar tissue of an ovule are able to survive the winter period, giving rise to seeds in the second growing period (Sarvas, 1962). We have illustrated this type of reproductive failure in artificial crossings of some hard pine species, including the crossing between P. sylvestris and P. mugo (Kormutak, 1984). A certain amount of normally developing ovules of a given conelet was necessary for its further development into mature cone, otherwise, female strobili dry and drop (Sarvas, 1962).

Obviously, the above described prezygotic reproductive block leading to abortion of incompatibly pollinated ovules is responsible for a reduced amount of seeds in cones of the putative hybrid swarm populations. It is also reasonable to suppose that this seed quantity parameter is the cause of the shortening of cone length in hybrid swarms. Our phenological observations ruled out the lack of pollination due to asynchronous flowering causing reduced seed setting. Only slight differences in the flowering periods of the two species have also been revealed by Boratyński et al. (2003) based on morphology of the reproductive organs in $P$. sylvestris and $P$. uliginosa. Striking differences in germination percentage of seeds from control populations $P$. mugo and $P$. sylvestris on the one hand and putative hybrid swarms on the other hand may be taken as an indirect evidence supporting the hybrid nature of the swarms. The fraction of germinating seeds of the hybrid 
swarms ranged between $10.91 \%$ and $39.55 \%$ averaging at $29,04 \%$. This figure is similar to that reported for the hybrid swarm of $P$. sibirica $\times P$. pumila in the Baikal region with $25 \%$ of filled seeds containing differentiated embryos. According to Goroshkevich et al. (2008) the above swarm represents $F_{1}$ hybrids whose proportion of seeds without embryos is 10-20 times more frequent than in the open pollinated progenies of the parental species. Also, the empty seed fraction in the natural hybrids $P$. sibirica $\times P$. pumila is estimated to be 6-8 times higher than in the parental species. These data are rather expressive compared to only 2 times higher frequencies of the underdeveloped and empty seeds in the evaluated progenies from open pollination of $P$. sylvestris and $P$. mugo hybrid swarms referred herein.The observed difference in seed germination potentials between pure species populations of the parental species $P$. sylvestris and $P$. mugo and their hybrid swarms was not only due to a higher frequency of empty seed formation in hybrid swarms, but also because of a higher content of filled, but non-germinating seeds of the latter. This corroborates our earlier finding concerning a higher frequency of abortive embryogenesis in the hybrid swarms than in the parental species $P$. sylvestris and P. mugo (Kormutak et al., 2008a). Underdeveloped embryos lacking cotyledons were present in seeds of the hybrid swarms along with a small amount of morphologically differentiated and physiologically mature seeds. This finding supports the conclusion made by McWilliam (1959) and Krugman (1970), who postulate that in crosses between hard pines, reproductive failure may occur at almost any stage, starting from the failure of the pollen to germinate on the nucellus to the abortive development of the embryo. It is apparent that prezygotic hybridological barriers and/or incompatibility operates within a group of hard pine species only between genetically distant species. In closely related species like $P$. sylvestris and $P$. mugo, embryo inviability may also account for hybridological failure. It is worth mentioning in this context that embryo inviability operates as the principal barrier to hybridization of genetically less differentiated soft pine species (Kriebel, 1967).

Of the four putative hybrid swarm populations of $P$. sylvestris and $P$. mugo occurring in Slovakia, only the hybrid swarm Medzi Bormi near Zuberec was subjected to morphometric and cytological analyses. Based on needle cross-section data, Viewegh (1981) postulates the hybrid nature of the swarm. The presented experimental data on pollen viability and seed quality may be taken as an additional evidence of the kind. However, in order to settle this matter definitely, molecular screening of the hybrid individuals of the swarms is necessary, preferably using DNA markers. Recent data by Celiński et al. (2017) indicate that neither chloroplast nor mitochondrial genomes harbour the potential for discrimination between $P$. mugo and $P$. uliginosa. The latter is supposed to evolve as the product of ancient hybridization between $P$. sylvestris and the taxa from $P$. mugo complex (Christensen, 1987). Therefore, highly challenging remains the need to involve into screening of these hybrids the nuclear genome (Celiński et al., 2017).

\section{Conclusions}

In the present study we have repeatedly proved the lowered viability of pollen grains in the P. mugo - P. sylvestris putative hybrid swarm individuals enforcing the concept of reduced fertility of the interspecific hybrids of pines. Being representatives of the subgenus Diploxylon (hard pines), the species $P$. sylvestris and $P$. mugo are postulated to be reproductively isolated by a strong prezygotic barrier based on the inability of pollen grains to penetrate nucellar tissue of an ovule and to accomplish fertilization of the egg cell. However, artificial hybridization experiments have shown that gametophytic incompatibility between these species is not complete and that there exists partial compatibility between $P$. sylvestris and P. mugo (Kormutak et al., 2017). It seems reasonable therefore to expect that open pollination progenies of the putative hybrid swarm of $P$. sylvestris and $P$. mugo contain a small amount of the seeds from hybridization between these species along with the seeds originating from mutual intercrossing of the putative hybrid swarm individuals. Both the seeds with non-differentiated embryos and empty seeds in the open pollination progenies may be taken for the indication that except of prezygotic barrier, a postzygotic block operates in the above putative hybrid swarm based on abortive changes of the embryos during early stages of their development. This aspect of the putative hybrid swarm embryogeny needs to be clarified further employing extensive cytological investigation.

\section{Acknowledgements}

This study was funded by the VEGA Grant Agency, project no. 2/0063/17.

\section{References}

Bacilieri R, A Ducousso, RJ Petit and A Kremer (1996) Mating system and asymetric hybridization in a mixed stand of European oaks. Evolution 50:900-908 https://doi.org/10.1111/j.1558-5646.1996.tb03898.x

Blatny T and T Stastny (1959) Natural distribution of forest trees in Slovakia. Slovak Publisher of Agriculture Literature, Bratislava, $420 \mathrm{p}$ [In Slovak]

Bobowicz MA, BR Stephan and W Prus-Głowacki (2000) Genetic variation of F1 hybrids from controlled crosses between Pinus montana var. rostrata and Pinus sylvestris in anatomical needle traits. Acta Societatis Botanicorum Poloniae 69:207-214. https://doi.org/10.5586/asbp.2000.028

Boratyński A, K Boratyńska, A Lewandowski, Z Gołab and P Kiciński (2003) Evidence of the possibility of natural reciprocal crosses between P. sylvestris and P. uliginosa based on phenology of reproductive organs. Flora 198: 1227-1239

Buchholz JT (1944) The cause of sterility in cross-pollinations between certain species of pines. American Journal of Botany 31: 25

Businsky R (1999) Taxonomic essay in the Pinus mugo complex and its hybrid populations. Acta Průhoniciana 68:123-143

Celiński K, H Kijak, A Wojnicka-Półtorak, K Buczkowska-Chmielewska, J Sokołowska and E Chudzińska (2017) Effectiveness of the DNA barcoding approach for closely related conifers discrimination: A case study of the $\mathrm{Pi}$ nus mugo complex. Comptes Rendus Biologies 340:339-348 https://doi.org/10.1016/j.crvi.2017.06.002 
Chamberlain CJ (1935) Gymnosperms, Structure and Evolution. University of Chicago Press, Dover Publications, Inc. New York, $484 \mathrm{p}$ https://doi.org/10.5962/bhl.title.10239

Christensen KJ (1987) A morphometric study of the Pinus mugo Turra complex and its hybridization with P. sylvestris. Feddes Repertorium 98:623-635 https://doi.org/10.1002/fedr.19870981113

Christensen KJ and GH Dar (1997) A morphometric analysis of spontaneous and artificial hybrids of P. mugo $\times$ sylvestris (Pinaceae). Nordic Journal of Botany 17:77-86. https://doi.org/10.1111/j.1756-1051.1997.tb00291.x

Danusevichius D, V Marozas, G Brazaitis, R Petrokas and KI Christensen (2012) Spontaneous hybridization between Pinus mugo and Pinus sylvestris at the Lithuanian seaside: A morphological survey. The ScientificWorld Journal. https://doi.org/10.1100/2012/172407

Darwin Ch (1859) The origin of species by means of natural selection. John Murray, London, $440 \mathrm{p}$

Dogra PD (1967) Seed sterility and disturbances in embryogeny in conifers with particular reference to seed testing and tree breeding in Pinaceae. Studia Forestalia Suecica 45:68-96

Duffield JW (1952) Relationships and species hybridization in the genus Pinus. Zeitschrift für Forstgenetik und Forstpflanzenzüchtung 1:93-97

Goroshkevich SN (2004) Natural hybridization between Russian stone pine (Pinus sibirica) and Japanese stone pine (Pinus pumila). In: Sniezko R S, S Samman, D Schlarbaum and HB Kriebel (eds) Breeding and Genetics of Five-needle Pines: growth, adaptability, and pest resistance: IUFRO Working Party 2.02.15. Medford, 24-25 July 2001, pp 169-174

Goroshkevich SN, AG Popov and GV Vasilieva (2008) Ecological and morphological studies in the hybrid zone between Pinus sibirica and Pinus pumila. Annals of Forest Research 51:43-52

Kang K.-S, AD Bila, AM Harju and D Lindgren (2003) Estimation of fertility variation in forest tree populations. Forestry 76:329-344 https://doi.org/10.1093/forestry/76.3.329

Kormutak A (1984) Some cytological and biochemical aspects of interspecific incompatibility in pines (Pinus sp.). Acta Dendrobiologica, VEDA Publisher, Bratislava, $92 \mathrm{p}$

Kormutak A, J Bohovicova, B Vookova and D Gőmőry (2007) Pollen viability in hybrid swarms of Pinus mugo Turra and P. sylvestris L. Acta Biologica Cracoviensia, Series Botanica 49(1):61-66

Kormutak A, B Vookova, V Camek, P Bolecek and D Gőmőry (2008) Pollen size and viability in hybrid swarm populations of Pinus mugo Turra and P. sylves tris L. Thaiszia - Journal of Botany 18:93-100

Kormutak A, B Vookova, P Manka, J Salaj, V Camek and D Gömöry (2008a) Abor tive embryogenesis in hybrid swarm populations of Pinus sylvestris L. and Pinus mugo Turra. Trees 22:657-662 https://doi.org/10.1007/s00468-008-0223-x

Kormutak A, P Manka, B Vookova, T Salaj, V Camek, P Bolecek and D Gömöry (2009) Seed quality in hybrid swarm populations of Pinus mugo Turra and $P$. sylvestris L. Plant Systematics and Evolution 277(3-4):245-250 https://doi.org/10.1007/s00606-008-0121-0

Kormutak A, M Galgoci, P Manka, M Koubova, M Jopcik, M Sukenikova, P Bolecek and D Gőmőry (2017) Field-based artificial crossings indicate partial compatibility of reciprocal crosses between Pinus sylvestris and Pinus mugo and unexpected chloroplast DNA inheritance. Tree Genetics and Genomes 13(3), article no. 68, ISSN 1614-2942 https://doi.org/10.1007/s11295-017-1152-x

Kriebel HB (1967) The timing of the incompatibility reaction in interspecific crosses of Pinus strobus L. In Proceeding of 14th IUFRO Congress, Münich 1967, Part III, Sect 22:77-87

Krugman SL (1970) Incompatibility and inviability systems among some western North American pines. In Proceeding of IUFRO Section 22, Working Group Meeting on Sexual Reproduction of Forest Trees, Varparanta, Finland $13 \mathrm{p}$

Little EL and WB Critchfield (1969) Subdivisions of the genus Pinus (pines). USDA, Forest Service, Miscellaneous Publication no. 1144, 51 p

McWilliam JR (1959) Interspecific incompatibility in Pinus. American Journal of Botany 46:425-433 https://doi.org/10.1002/j.1537-2197.1959.tb07033.x

Mirov NT (1967) The genus Pinus. Ronald Press Company, New York, 602 p https://doi.org/10.2307/4004229
Moulalis D, C Bassiotis and D Mitsopoulos (1976) Controlled pollinations among pine species in Greece. Silvae Genetica 25(3-4):95-107

Politov DV, MM Belokon, OP Maluchenko, YS Belokon, VN Molozhnikov, LE Mejnartowicz and KV Krutovskij (1999) Genetic evidence of natural hybridization between Siberian stone pine, Pinus sibirica Du Tour, and dwarf Siberian pine, P. pumila (Pall.) Regel. Forest Genetics 6(1):41-48

Prus-Głowacki W and J Szweykowski (1980) Serological characteristics of some putative individuals from a Pinus sylvestris $\times$ Pinus mugo hybrid swarm population. Acta Societatis Botanicorum Poloniae 49(1-2):127-142 https://doi.org/10.5586/asbp.1980.011

Prus-Głowacki W, J Sadowski, J Szweykowski and I Wiatroszak (1981) Quantitative and qualitative analysis of needle antigens of Pinus sylvestris, Pinus mugo, Pinus uliginosa and Pinus nigra and of some individuals from hybrid swarm population. Genetica Polonica 22(4):447-454

Righter FI and P Stockwell (1949) The fertile species hybrid, Pinus murray-banksiana. Madrońo 10:65-69

Sarvas R (1962) Investigations on the flowering and seed crop of Pinus sylvestris. Communicationes Instituti Forestalis Fenniae 53:1-198

Sax K (1960) Meiosis in interspecific pine hybrids. Forest Science 6:135-138

Sax K and MJ Sax (1933) Chromosome number and morphology in the conifers. Journal of Arnold Arboretum 14:357-375 https://doi.org/10.5962/bhl.part.9959

Saylor LC and BW Smith (1966) Meiotic irregularity in species and interspecific hybrids of Pinus. American Journal of Botany 53(5):453-468 https://doi.org/10.1002/j.1537-2197.1966.tb07358.x

Somora J (1981) The mountain dwarf pine (Pinus mugo Turra) in the Tatra National Reserve (Distribution, shape, varieties). Collectiones of Publications of the Tatra National Reserve 22:31-76 [In Slovak]

Staszkiewicz J (1996) Natural hybrids of Pinus mugo $\times$ P. sylvestris (Pinaceae) in Tatra Mts. Fragmenta Floristica et Geobotanica, Series Polonica 3:23-30

Stebbins GL-Jr (1950) Variation and Evolution in Plants. Columbia University Press, New York, $643 \mathrm{p}$

Viewegh J (1981) Variability of Pinus mugo $\times$ Pinus silvestris hybrid swarm on peat-bog in Zuberec of the Orava region. Folia Dendrologica 8(81): 41-59 [In Czech]

Wachowiak W, K Celiński and W Prus-Glowacki (2005) Evidence of natural hybridisation between Pinus uliginosa and P. sylvestris in the sympatric population of the species. Flora 200:563-568 https://doi.org/10.1016/j.flora.2005.06.007

Wachowiak W, A Lewandowski and W Prus-Głowacki (2005) Reciprocal controlled crosses between Pinus sylvestris and P. mugo verified by a species-specific cpDNA marker. Journal of Applied Genetics 46(1):41-43

Wachowiak W, J Odrzykoski, Ł Myczko and W Prus- Głowacki (2006) Lack of evidence on hybrid swarm in the sympatric population of Pinus mugo and $P$. sylvestris. Flora 201:307-316 https://doi.org/10.1016/j.flora.2005.08.004

Wachowiak W and W Prus-Głowacki (2008) Hybridisation processes in sympatric populations of pines Pinus sylvestris L., P. mugo Turra and P. uliginosa Neuman. Plant Systematics and Evolution 271(1-2):29-40 https://doi.org/10.1007/s00606-007-0609-z

White TL, WT Adams and DB Neale (2009) Forest Genetics. Cromwell Press Group, Trowbridge, UK, $682 \mathrm{p}$ 